\title{
PSYCHOPHYSICAL EVIDENCE FOR LOW-LEVEL PROCESSING OF ILLUSORY CONTOURS AND SURFACES IN THE KANIZSA SQUARE
}

\author{
Birgitta Dresp and Claude Bonnet \\ Laboratoire de Psychologie Expérimentale, Université Paris V, CNRS, 28 rue Serpente, \\ 75006 Paris, France
}

(Received 23 April 1990; in revised form 3 December 1990)

\begin{abstract}
Increment thresholds were measured on either side of one of the illusory contours of a white-on-black Kanizsa square and on the illusory contour itself. The data show that thresholds are elevated when measured on either side of the illusory border. These elevations diminish with increasing distance of the target spot from the white elements which induce the illusory figure. The most striking result, however, is that threshold elevations are considerably lower or even absent when the target is located on the illusory contour itself. At an equivalent position in a control figure where no illusory contour is visible, such a threshold decrease does not occur. The present observations add empirical support to low-level explanations of illusory contour perception.
\end{abstract}

Increment threshold Brightness perception Illusory contours

\section{INTRODUCTION}

Measuring increment thresholds (Cornsweet, 1962) for the detection of a small light spot generally constitutes a means of investigating sensitivity variations as a function of the luminance of the background on which the light target is added. Increment threshold variations furthermore are supposed to reflect changes in visual sensitivity due to differences in brightness although it is, in this case, not always possible to make specific predictions (Cornsweet \& Teller, 1965; Fiorentini, 1972). When measured on either side of a luminance border, thresholds generally tend to decrease when the distance between the light target and the border increases (Aulhorn \& Harms, 1956; Fiorentini \& Zoli, 1966; Van Essen \& Novak, 1974; Wildmann, 1974). These local threshold elevations may partly be a consequence of lateral interactions between cells coding luminance across the edge, partly they may be related to other factors such as stray light (e.g. Heinemann, 1972; Fiorentini, 1972; Wildmann, 1974).

In this study, increment thresholds were measured on either side of an illusory border in the Kanizsa square and on that border in order to test in how far threshold variations may be equivalent to those observed near "real" edges and to what extent lateral interactions between luminance specific cells may account for the perception of illusory forms like the Kanizsa square (cf. Brigner \& Gallagher, 1974; Coren \& Theodor, 1977; Spillmann, Fuld \& Neumeyer, 1984).

\section{EXPERIMENT 1}

\section{Subjects}

Two trained subjects participated in this experiment. One of the observers was the first author. Both subjects had normal vision.

\section{Material}

The stimuli were presented binocularly on a high resolution video monitor (Visionor model M 51 CHR no. 1007, Lille, France). They were generated through a PC compatible computer (Olivetti M 24) using a special graphics adaptor (Galaxy ref. SA-1019A, Evroz, Tel Aviv) providing a display of 1024 (horizontally) $\times 768$ (vertically) pixels at $60 \mathrm{~Hz}$ frame rate (noninterlaced). The pixel size was $0.33 \times 0.33 \mathrm{~mm}$. The background patterns on which the incremental light spot $(0.025 \mathrm{deg}=1$ pixel $)$ was added were two versions of the Kanizsa square. One represented the classic pattern in which illusory contours are perceived, the other one did not give rise to illusory contour perception (Fig. 1a and b). Recent data obtained with the same stimuli show that both types of display give rise to local brightness enhancement 
(a)

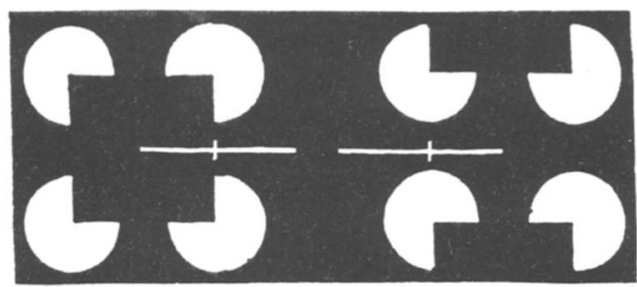

Fig. 1. The two versions of the Kanizsa square used in this experiment. (a) The authentic Kanizsa pattern giving rise to illusory contour perception and apparent contrast within and outside the square. Increment thresholds were measured on the horizontal median axis at the following distances from one of the illusory contours: $-2,2,-4,4,-8,8$, $-16,16,-40,48$ pixels (- refers to positions inside the square) as well as on the contour itself. (b) A control version in which increment thresholds were measured on the axis where no illusory contour is seen. The angular size of 1 pixel was $0.025 \mathrm{deg}$.

(Dresp, Lorenceau \& Bonnet, 1990). The displays were exposed continuously in the centre of the screen. The luminance of the white inducing elements was $21 \mathrm{~cd} / \mathrm{m}^{2}$; that of the dark background was $2 \mathrm{~cd} / \mathrm{m}^{2}$. The diameter of the pacmen was $1.50 \mathrm{deg}(60$ pixels) in both versions of the display. Inter-pacman gap (edge to edge) was $0.50 \mathrm{deg}$ ( 20 pixels). Gray levels of the test pixel were obtained by combinations of $R-G-B$ signals carefully calibrated with a CS 100 Minolta photometer. The subject was placed in front of the screen at a viewing distance of about $75 \mathrm{~cm}$.

\section{Procedure}

Thresholds were measured at different points inside and outside the Kanizsa square as well as on the illusory contour itself. In the control pattern, measurements were taken at equivalent points where no illusory contour was seen. The test pixel was shifted horizontally across the median axis of the figures. A small gray circle at liminal contrast to the background served as the fixation mark between trials. The subject's head position was stabilized by means of a head and chin rest. Exposure time of the test pixel was set at about $170 \mathrm{msec}$ (10 frames). Within each session one or more (depending on the length of the session thresholds were measured on a homogeneous dark field $\left(2 \mathrm{~cd} / \mathrm{m}^{2}\right)$. The purpose of these controls was to neutralize fluctuations of the physical luminance output of the screen on one hand and sensitivity fluctuations of the subject on the other. Each threshold measured in one of the Kanizsa displays was related to a control threshold established within the same experimental session. The experiment was run in a dark room and the subject was dark-adapted at the beginning of each session.

Thresholds were measured by means of an adaptive yes/no procedure devised from Tyler (1987). This staircase procedure leads to a rapid convergence of the gray values near the asymptotic threshold level. Stopping criteria were continuously calculated on the 15 preceeding trials according to the following principles. A threshold was obtained when two conditions were met: the slope of the function relating the values of the stimulus to the rank of the trial had to be equal to zero \pm 0.1 ; the percentage of correct detections had to be $75 \pm 10 \%$. An average of 50 trials was necessary to reach a threshold. At each point in each figure condition, three thresholds were measured.

\section{Results}

Sixty-six thresholds measured at several points in the Kanizsa square and in the control display and 26 measurements on a homogeneous background were obtained with one of the subjects. Thirty thresholds in the two Kanizsa patterns and 14 measurements on a blank field were recorded with the second observer. Detection performances were quite stable within and between experimental sessions. Standard deviations of the thresholds measured on the homogeneous background were $0.53 \mathrm{~cd} / \mathrm{m}^{2}\left(m=4.89 \mathrm{~cd} / \mathrm{m}^{2}\right)$ for one subject and $0.82 \mathrm{~cd} / \mathrm{m}^{2}\left(m=5.98 \mathrm{~cd} / \mathrm{m}^{2}\right)$ for the other one. Figures 2 and 3 show threshold ratios as a function of the target position. Each point in each figure represents the mean value of

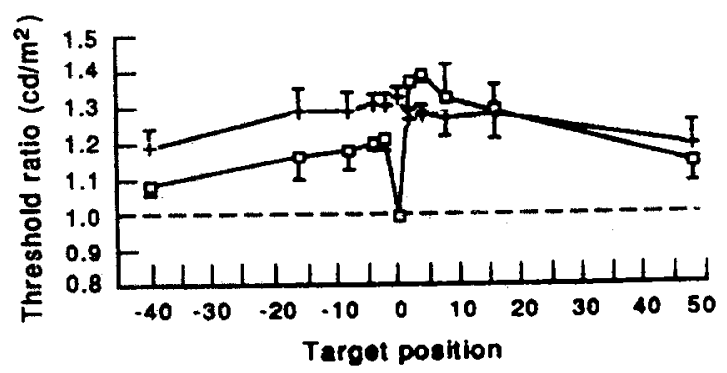

Fig. 2. Threshold ratios (threabold with beckground pattern/threshold on homopeneous feld) of subject B.D. as a function of target position and type of backyround pattern. Threchold elevatiom ane lower on the inser side of an illusory contour in the Kanises square. No elevation is observed on the illusory border itwalf. In both the Kanizas equare $(\square)$ and the control $(+)$ dicplay, thrmold elevations diminish with incruaring diatance of the taryet from the contrast inducing elements. The bars represent standard errors $(\sigma / \sqrt{N})$. A yes/no procedure was used. 


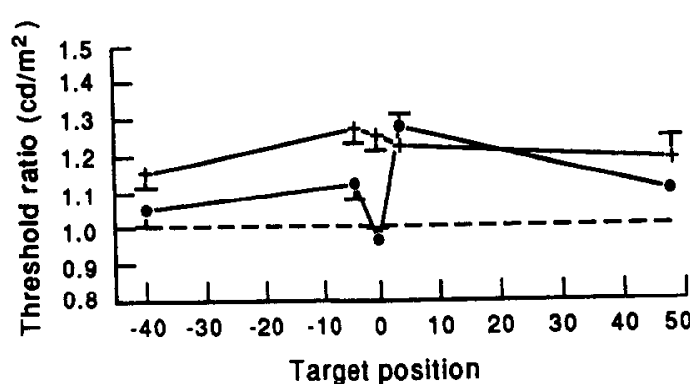

Fig. 3. Threshold ratios of subject T.N. as a function of target location and type of background pattern. The curves show the same tendencies as those described for subject B.D. in Fig. 2. The bars represent standard errors. A yes/no procedure was used. (O) Kanizsa square; $(+)$ control figure.

three ratios. The detection performances of the two observers show excellent inter-subject coherence.

Threshold elevations are observed in both displays at target positions close to the white elements. These elevations decrease with increasing distance between the target position and the inducing elements. Comparing results obtained on the outer side of the Kanizsa square to measurements taken on the inner side, threshold elevations appear to be systematically lower when the target is located within the illusory square. This observation is consistent with earlier findings reported by Coren and Theodor (1977).

On the illusory contour itself, thresholds do not differ from those obtained on a homogeneous dark background. At the equivalent target position in the control figure where no illusory contour is visible, such a threshold decrease is not observed.

\section{EXPERIMENT 2}

This second experiment was run to ensure that the results obtained in the first study are not affected by response bias due to the threshold procedure. Given the fact that thresholds obtained through the adaptive staircase method described above depend on the observer's willingness to respond "yes" or "no", a twoalternative temporal forced-choice (2AFC) procedure was used for the purpose of control in the second experiment.

\section{Subjects}

Two trained observers (the authors) took part in the second experiment. B.D. (29-yr old) has normal vision, C.B. (52-yr old) has normal presbyopic vision.

\section{Material and procedure}

Stimuli, apparatus as well as general experimental conditions were identical to those of the first experiment. Thresholds were measured by means of two different procedures: the adaptive yes/no method used in the first experiment and a 2AFC procedure (BestPEST; Lieberman \& Pentland, 1982). The latter was run with a constant number of 60 trials for each target position. The criterion for incrementing and decrementing the light spot was the maximumlikelihood for the threshold value. The intensity of the stimulus at the last trial was considered as the threshold.

Thresholds for the detection of the light target were measured at two points inside and at two points outside the Kanizsa square as well as on the illusory contour itself. As in the first experiment, the test pixel was shifted horizontally across the very middle of the illusory contour locus. In the control figure, measurements were taken at equivalent points. With each of the two procedures, one threshold was recorded for each target position and each subject.

\section{Results}

The data of this second experiment show that the same effects as those observed in the first study can be obtained with both threshold procedures (Figs 4a, b and 5a, b). Thresholds for the detection of the target are elevated when measured on either side of an illusory border in the Kanizsa square. These elevations diminish with increasing distance of the light spot from the white elements which induce the illusory figure.

Threshold elevations are considerably lower (subject C.B.) or absent (subject B.D.) when the target is located on the illusory contour itself. On the contrary, at an equivalent position in the control figure where no illusory contour occurs, considerable threshold elevations are recorded.

The results of this second study clearly show that these effects are obtained with both types of procedure (yes/no and $2 \mathrm{AFC}$ ) and therefore validate the data of the first experiment.

\section{CONCLUSIONS}

The threshold elevations recorded close to the borders of an illusory contour appear to diminish with increasing distance between the target spot and the inducing elements. This result is similar to findings obtained with luminance 



Fig. 4. (a) Threshold ratios obtained in the second experiment with a 2 AFC procedure (subject B.D.). The curves show the same effects as those reported in the first experiment with a different threshold procedure (yes/no). Each point in the curves represents one ratio, standard errors could therefore not be calculated. (b) represents results obtained in the second experiment with the yes/no procedure (subject B.D.). Comparison between (a) and (b) shows that both procedures lead to the same type of result.

(O) Kanizsa square; (+) control figure.


Fig. 5. Results recorded with subject C.B. in the second experiment. (a) 2AFC procedure and (b) yes/no procedure. The curves follow the same tendency as the one reported with subjects T.N. and B.D. in the first and second experiment. Comparison between (a) and (b) does not reveal any influence of the type of threshold procedure on the observed efiects. Each point in each curve represents one threshold ratio. (O) Kanizsa square; $(+)$ control figure. step patterns (cf. Van Essen \& Novak, 1974) The threshold elevations are likely to be a consequence of lateral interactions between cells coding the rate of change in luminance across the borders of the inducing elements. Such luminance specific mechanisms may account for the perception of differences in brightness in the stimuli (cf. Fiorentini, 1972).

The fact that threshold elevations are considerably lower or even absent when the target is located on the illusory border shows that elevations recorded on either side of it cannot be explained by stray light. This result is compatible with phenomenal and psychophysical observations which suggest that the mechanisms underlying illusory contour perception are essentially determined by the collinearity and proximity of parts and not by their luminance (Prazdny, 1983; Zucker, Stevens \& Sander, 1983; Zucker \& Davis, 1988). The determining influence of collinearity on the activity of orientation-selective cells has been demonstrated in recent electrophysiological studies (cf. Peterhans \& Von der Heydt, 1989; Von der Heydt \& Peterhans, 1989). As a whole, the present findings sustain views suggesting that illusory contour perception may involve two separate processes: one giving rise to brightness differences and one generating illusory contours (cf. Day \& Jory, 1980). They give general support for low-level explanations of illusory contour perception.

Acknowledgements - The authors should like to express their gratitude to Michael J. Morgan for his helpful comments on an earlier version of this paper.

\section{REFERENCES}

Aulhorn, E. \& Harms, H. (1956). Untersuchungen über das Wesen des Grenzkontrastes. Berichte der Deutschen Ophtalmologischen Gesellschaft. Heidelberg.

Brigner, W. L. \& Gallagher, M. B. (1974). Subjective contour: Apparent depth or simultaneous contrast? Perceptual and Motor Skills, 38, 1047-1053.

Coren, S. \& Theodor, L. H. (1977). Neural interactions and subjective contours. Perception, 6, 107-111.

Cornsweet, T. N. (1962). The staircase method in psychophysics. American Journal of Psychology, 75, 485-491

Cornsweet, T. N. \& Teller, D. Y. (1965). Regulation of increment threshold to brightness and luminance. Journal of the Optical Society of America, 55, 1303-1308.

Day, R. H. \& Jory, M. K. (1980). A note on a second stage in the formation of illusory contours. Perception and Psychophysics, 27, 89-91.

Dresp, B., Lorenceau, J. \& Bonnet, C. (1990). Apparent brightness enhancement in the Kaniza square with and without illusory contour formation. Perception, 19, 483-489. 
Fiorentini, A. (1972). Mach band phenomena. In Jameson, D. \& Hurvich, L. M. (Eds.), Handbook of sensory physiology: Visual psychophysics (pp. 188-201). New York: Springer.

Fiorentini, A. \& Zoli, M. T. (1986). Detection of a target superimposed to a step pattern of illumination. Atti della fondazione Giorgio Ronchi, 22, 338-356.

Heinemann, E. G. (1972). Simultaneous brightness induction. In Jameson, D. \& Hurvich, L. M. (Eds.), Handbook of sensory physiology: Visual psychophysics (pp. 146-169). New York: Springer.

Lieberman, H. R. \& Pentland, A. P. (1982). Microcomputer-based estimation of psychophysical thresholds: The BestPEST. Behavior Research Methods and Instrumentation, 14, 21-25.

Peterhans, E. \& Von der Heydt, R. (1989). Mechanisms of contour perception in monkey visual cortex-II. Contours bridging gaps. Journal of Neuroscience, 9 , 1749-1763.

Prazdny, K. (1983), Illusory contours are not caused by simultaneous brightness contrast. Perception and Psychophysics, 34, 403-404.

Spillman, L., Fuld, K. \& Neumeyer, C. (1984). Brightness matching, brightness cancellation and increment threshold in the Ehrenstein illusion. Perception, 13, 512-520.

Tyler, C. W. (1987). Analysis of visual modulation sensitivity-III. Meridional variations in peripheral flicker sensitivity. Journal of the Optical Society of America, A4, 1612-1619.

Van Essen, J. S. \& Novak, S. (1974) Detection thresholds within a display that manifests contour enhancement and brightness contrast. Journal of the Optical Society of America, 64, 726-729.

Von der Heydt, R. \& Peterhans, E. (1982). Mechanisms of contour perception in monkey visual cortex-I. Lines of pattern discontinuity. Journal of Neuroscience, 9, 1731-1748.

Wildmann, K. N. (1974). Visual sensitivity at an edge. Vision Research, 14, 749-755.

Zucker, S. W. \& Davis, S. (1988). Points and end-points: A size-spacing constraint for dot grouping. Perception, 17, 229-247.

Zucker, S. W., Stevens, K. Sander, P. (1983). The relation between brightness and proximity in dot patterns. Perception and Psychophysics, 34, 513-522. 